\title{
Information exchange model for remote consulting systems in the Russian Federation
}

\author{
Igor Ilin ${ }^{1}$, Victoriia Iliashenko ${ }^{1, *}$, and Oksana Iliashenko ${ }^{1}$ \\ ${ }^{1}$ Peter the Great St.Petersburg Polytechnic University, St.Petersburg, Polytechnicheskaya, 29, 195251, \\ Russia
}

\begin{abstract}
One of the most important and promising directions of introducing information and telecommunication technologies into the healthcare system in Russia is the development of a methodology for prolonged monitoring of the patient's condition and remote consultation by the attending physician. This is due to the fact that many diseases that hold leading positions in the structure of morbidity, disability and mortality of patients require active monitoring of the patient, including during the period between planned visits to the clinic. The creation of such systems can not only prevent medical errors, facilitate rapid response, but also helps to solve the most global problem in any chronic disease - poor adherence to treatment. Therefore, the development and implementation of a remote consultation system based on telemedicine technology will reduce the burden on the outpatient unit by reducing the need to visit a doctor and significantly improve the quality of medical care. However, the use of telemedicine technologies requires the existing business process reengineering of medicine center and process of information exchange between participants in this process - regional and federal medical centers. The article suggests the approach to forming information exchange model between federal and regional medical centers using telemedicine technologies for remote monitoring.
\end{abstract}

\section{Introduction}

In the 20th century, the main driver of medicine was the development of pharmaceuticals, in particular the emergence of biomedical drugs and the therapy of oncological diseases, as well as the improvement of diagnostic methods and high-tech surgical tactics. Today, the technologies that are developing at the junction of modern health concepts and Health 4.0 are making an increasing contribution to improving the quality of care and increasing the life expectancy of patients. Telemedicine is one of these technologies. Telemedicine solutions are currently actively developing.

There are a lot of definitions of the term "Telemedicine". All definitions can be classified into three groups:

- from a legal and political point of view;

- from the information point of view;

\footnotetext{
* Corresponding author: ilyashenko.vm@edu.spbstu.ru
} 
- from a medical point of view.

Let's consider each of the groups in more detail. A formal definition is important from a legal and political point of view. As part of the World Health Organization's telemedicine policy, the following definition is proposed: "Telemedicine is a comprehensive concept for health systems, services and activities that can be remotely transmitted through information and telecommunication technologies, for the development of global health, disease control, as well as education, management of research in the field of medicine [1].

From the information point of view, the following definitions of the concept of telemedicine can be distinguished:

- Telemedicine is the use of computers, the Internet and other communication technologies to provide medical care to patients at a distance [2];

- telemedicine is an integrated system of medical care using telecommunications and computer technology instead of direct contact between the medic and the patient [3];

- telemedicine is the use of telecommunications and computer technology, combined with the experience of medical professionals to facilitate the provision of medical care in remote areas [4];

- Telemedicine is the process of providing medical care to patients anywhere in the world by combining communication technology with medical experience [5].

The description of the term "telemedicine" from a medical point of view may have the following interpretations:

- telemedicine is medical care conducted at a distance: images are transmitted in such a way that the patient and the doctor do not need to be in the same place at the same time [6];

- telemedicine is a "distance medicine", which includes the diagnosis, treatment and training [7]. In our opinion, the development of telemedicine is based on the use of modern medical technologies, information processing methods combined with advances in telecommunications technology. In this study we will use the concept of telemedicine, proposed by S.V. Frolov: "Telemedicine is an applied area of medical science related to the development and application in practice of methods of remote provision of medical care and the exchange of specialized information based on the use of modern telecommunication technologies" [8].

From the above definition, it can be seen that telemedicine is based on three main components: medicine, informatics (information technology) and telecommunications technologies (see Error! Reference source not found.).

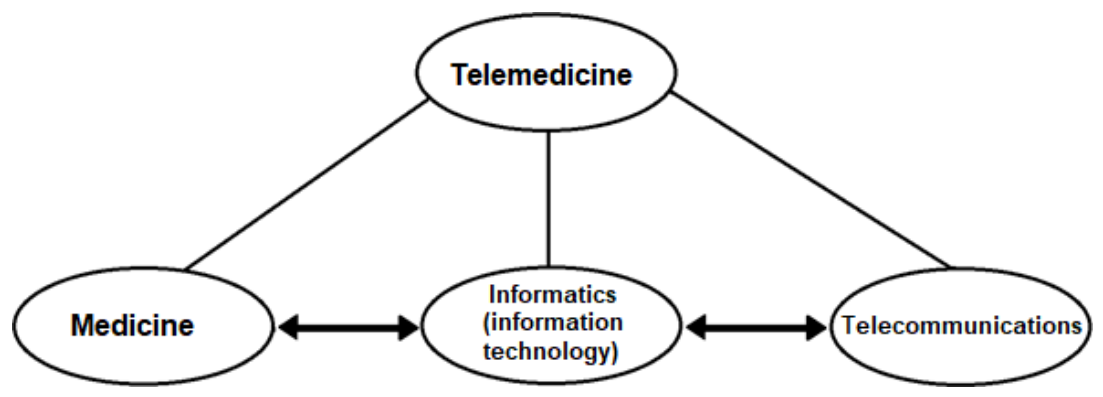

Fig. 1. The main components of telemedicine.

Based on the above definitions, the main features of telemedicine are:

- use of specialized equipment, which collects, transforms, stores, transmits and processes medical information;

- the availability of a telecommunications network that allows communication between providers and consumers of medical information; 
- application of specialized software that links all the elements of the system into a single complex;

- the presence of a staff of specialists (doctors, electronics engineers, programmers, etc.), providing information and technical support of the complex, its effective application in solving various medical problems.

In the late 50s of the last century, medical specialists began using television in clinics. Consider the history of the development of major foreign telemedicine solutions of the 20th century:

- 1959 - for the first time in the United States, television communications were used to consult a psychiatrist;

- 1959 - an image of a lung fluorogram along a coaxial cable was transmitted from the USA to Montreal;

- 1964 - an interactive video link is established between the psychiatric institute in Omaha and the hospital, which is located $180 \mathrm{~km}$ from it.

- 1965 - telemedicine manipulation by Dr. Michael E. De Bakeya, who, while in the United States, prepared, monitored and monitored the open heart operation in Geneva (Switzerland) through interactive television systems;

- 1967 - established a complete telemedicine system linking the Boston airport medical terminal to the Massachusetts hospital;

- late 60's, early 70's. - development of projects and programs that allow testing the potential capabilities of telemedicine in a specific medical field, such as: INTERACT (Hanover); Puerto Rican telemedicine program in Ponco (Puerto Rico); program STARPAHC (Space Technology Applied to Rural Papago Advanced Health Care) (South Arizona);

- 1970-80 years. - NASA carried out the transfer of clinical data through television in Arizona, Boston and Canada.

The greatest development of telemedicine was in the United States of America, Scandinavian countries and Canada, where there are geographically remote areas and high demands for medical care. Telemedicine allows you to effectively provide medical advice and medical assistance in remote areas to those patients for whom the timeliness of the intervention is the decisive factor. The given problem is actual and for the Russian Federation in connection with its extensive territory and rather low level of development of an infrastructure of the remote settlements. In our country, the concept of telemedicine began its embodiment in the framework of space exploration programs. Here telemedicine technologies were used as part of intra-cabin telemetry systems and automatic medical control systems. Information from such systems was transmitted to the Flight Control Center through a remote monitoring service.

To date, the subject of research in the field of telemedicine is extensive: global telemedicine; testing of telemedicine systems; mobile telemedicine systems; training with telemedicine; telemedicine in orthopedics, etc.; teleradiology; forms of collection for clinical data for the provision of medical care at a distance, etc. [9].

Telemedicine is one of the areas that can transform the relationship between the provider and the patient. The introduction of telemedicine technologies will in the future improve the results of medical care and reduce unnecessary costs. Telemedicine includes a number of applications and services using two-way video, e-mail, smartphones, wireless tools and other types of telecommunications technologies. Historically, telemedicine has been seen as a new technology in hospitals to help patients in remote areas. At present, the use of telemedicine has been integrated into the activities of specialized departments of hospitals, home medical institutions, private doctors' offices, as well as houses and workplaces of consumers of medical services.

Telemedicine is one of the areas that can transform the relationship between the provider and the patient. The introduction of telemedicine technologies will in the future improve the 
results of assistance and reduce unnecessary costs. Telemedicine includes a number of applications and services using two-way video, e-mail, smartphones, wireless tools and other types of telecommunications technologies. Historically, telemedicine has been seen as a new technology in hospitals to help patients in remote areas. At present, the use of telemedicine has been integrated into the activities of specialized departments of hospitals, home medical institutions, private doctors' offices, as well as houses and workplaces of consumers of medical services. Some of the main advantages of introducing telemedicine technologies you can find below [10]:

- increasing the availability of medical care for both residents of remote regions and for older people;

- improving the quality of care with access to specialized providers of health services;

- reduction of the time of diagnosis;

- increasing the level of well-being and preventive care through remote monitoring at home;

- increase the effectiveness of management of the provision of medical care. By treating patients remotely, medical providers and patients overcome the distance and time barriers that separate them, which in turn reduces costs for both parties.

All these positive moments allow us to realize the ideas of value and personalized medicine.

In Russia, the introduction of telemedicine technology into medical practice is relevant for a number of reasons:

- the length of the Russian Federation;

- high mortality from cardiovascular and oncological diseases;

- the obligation to monitor the health status of patients who require high-tech and specialized medical care;

- shortage of specialists of a narrow profile, especially in the regions.

The introduction of telemedicine technologies implies an increase in medical and economic efficiency. At the same time, the management of the introduction and development of the remote monitoring system is accompanied by a number of difficulties. When implementing a remote monitoring system, the systematization of business processes both within the medical organization and between participants in the process at the level and federal levels. Transformation model of information exchange, corresponding to the modified business processes. It is necessary to justify the proposed model of information exchange from the standpoint of economic efficiency and applicability in the Russian Federation.

\section{Analysis of the telemedicine services market development in Russia}

Telemedicine is one of the fastest growing healthcare segments in the world (about $20 \%$ per year). The number of patients using telemedicine services will increase to 7 million by 2018 , IHS company experts say [11]. In Europe, the penetration rate of technology today is about $30 \%$, and by 2020 will reach $50 \%$. By 2019, the world telemedicine market will increase to \$ 44 billion (forecast BBC Research). In 2016, its volume was approximately $\$ 18$ billion, according to P \& S Market Research. The potential of the Russian market of telemedicine services MTS estimated at 18 billion rubles a year. About half of the doctors are positive about this format of care, found in a study in MAR Consult. 35\% of respondents are still negative, another 15\% are undecided. According to expectations "Rostec", the volume of the market, including equipment, software and telemedicine services, may amount to 300 billion rubles by 2020 [12]. 
In 2016, about 1.25 million teleconsultations were conducted in the United States (evaluation by the American Telemedicine Association). In Russia, after the adoption of the law, more than 1 million consultations can be provided, according to some forecasts, by the end of 2018. It is expected that the scale of savings will be comparable.

In order for telemedicine to work, it is necessary to prepare the infrastructure (to provide clinics with Internet connection and equipment), as well as the patients themselves, to this format of interaction with the doctor, in addition to the regulatory framework. In parallel with the advent of telemedicine platforms, the introduction of telemedicine into voluntary insurance policies and social packages of companies for employees has already begun on the market.

Potentially, the telemedicine services market may become a new field of activity for IT start-ups, although it is still difficult to build an effective business model. There are obvious difficulties in attracting medical personnel to such projects and with the promotion of services, where due to specificity, not all the usual marketing tools are available. To launch the project of teleconsultations "doctor-patient" from scratch, investments in the development of technology (about 20-30 million rubles), in the creation of infrastructure (doctors, methodology, training, quality control, technical support, etc.) and in maintenance of operational activities - on the whole at least 50 million rubles., Denis Shvetsov, director of the development of the network of clinics "Doctor near", estimates.

\section{Statistics on the use of telemedicine services in the market of commercial medicine}

As a result of a survey conducted among commercial health care providers, more than $30 \%$ of respondents intend to expand the range of medical services in the long term to 2020 (see Fig.2). Among them, $44 \%$ of the assortment expansion will be connected with telemedicine [13]. Another $56 \%$ of participants plan to open a full adult or children's hospital, $33 \%$ - the launch of pediatrics, and $22 \%$ - the strengthening of the surgical direction and the opening of pediatric surgery. Pediatrics is a popular area for the development of activities both in the GPL and in the regions. Many respondents have already opened and in the future are ready to expand the list of services in this area through the development of children's hospitals, child surgery departments, etc. $22 \%$ of respondents also noted plans to expand diagnostic services, some of which are related to the acquisition of new equipment. In addition, the respondents indicated oncology, industrial medicine, medical tourism. As for the other planned projects (improving operational efficiency, marketing projects implementation, service improvement), they practically do not differ from those already implemented. The only difference is that some clinics have already implemented such projects over the past year and a half, while others are just preparing for it. It should be noted the tendency to expand B2B services in private clinics. Slightly more than $30 \%$ of respondents indicated that in the medium term they plan to strengthen the direction of working with business. Half of them spoke about projects for the management of individual clinics and large medical organizations. 


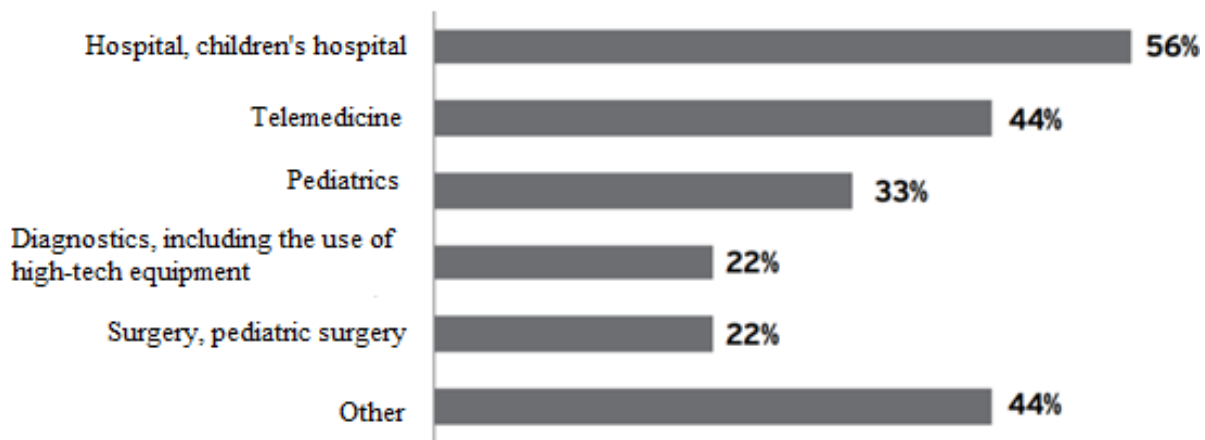

Fig. 2. Trend of medicine services spread in commercial clinics till 2020 years in Russian Federation [13].

It should be noted that in Russia the introduction of telemedicine technologies is accompanied by a number of difficulties.

- the use of telemedicine services requires reengineering of business processes, the formation of requirements for information exchange, the development of the model of information exchange and IT-infrastructure;

- lack of the required availability of telemedicine technologies. Only about $20 \%$ of doctors working in polyclinics, dispensaries, hospitals, departments can conduct remote consultations with equipment for audio communication and ECG reception in patients. To doctors of cardiological emergency medical teams this technology is more accessible, but also not for everyone. Less than half of cardiologists in medical institutions of the health care system can apply magnetic resonance therapy (Table 1);

Table 1. Proportion of cardiologists who have access to some modern medical technologies (\%).

\begin{tabular}{|c|c|c|c|c|c|}
\hline \multirow{2}{*}{$\begin{array}{l}\text { For } \\
\text { cardiologists } \\
\text { available: }\end{array}$} & \multicolumn{4}{|c|}{ Work place } & \multirow[t]{2}{*}{ Total } \\
\hline & $\begin{array}{l}\quad \text { Polyclinic } \\
\text { and } \\
\text { cardiological } \\
\text { clinic }\end{array}$ & $\begin{array}{l}\text { Cardiological } \\
\text { and therapeutic } \\
\text { department of } \\
\text { the hospital, } \\
\text { department of } \\
\text { medical high } \\
\text { school }\end{array}$ & Ambulance & $\begin{array}{l}\quad \text { Other } \\
\text { work } \\
\text { place }\end{array}$ & \\
\hline telemedicine & 28.6 & 50.0 & 4.8 & 40.0 & 35.9 \\
\hline $\begin{array}{l}\quad \text { use of } \\
\text { magnetic } \\
\text { resonance } \\
\text { therapy }\end{array}$ & 46.7 & 42.6 & - & 16.7 & 36.0 \\
\hline
\end{tabular}

- most of the diseases can't be diagnosed remotely, even if there are analyzes and studies. The lack of inspection reduces the correctness of the diagnosis, eliminates tactile contact; - the development of a legislative base for the provision of telemedicine services is required.

\section{Results}

\subsection{Results of telemedicine technologies application in Russia in $\mathbf{2 0 1 8}$}

Today in the Russian healthcare, practical experience has already been accumulated in the telemedicine centers organization in order to provide various types of medical services. Various telemedicine services are being developed: Pediatric 24/7, Online Doctor, etc. 
Telemedicine programs are successfully being implemented in Arkhangelsk, Voronezh, Chelyabinsk regions, St. Petersburg, Mordovia, etc. Today in Russia there are more than 50 telemedicine centers. There is an experience of using telemedicine methods in the operating room [14]. Doctors from Primorskiy region conducted the first in 2018 telemedicine consultations. In the regional clinical center of medical assistance specialized types two tele bridges connected Vladivostok with Novosibirsk and Moscow were held.

Telemedicine centers of federal medical centers are actively developing. For example, the Scientific and Advisory Telemedicine Center of the NMI of the SSX works with regional inventory items. During this consultation, doctors have the opportunity to quickly exchange medical information about the patient (extracts, electrocardiograms, roentgenograms, video recordings, expert opinions, test results and more). Gradually telemedicine services are started, providing remote monitoring of the patient's health by means of individual devices, "alarming" buttons for the elderly. For example, the "Doctor near" together with "CardiRu" gives the clients the opportunity to remove the ECG remotely and receive a transcript of the results together with the doctor's recommendation. However, this segment is developing poorly, on the one hand, due to high costs, on the other - because of obstacles on the way of domestic developers to the end consumer. There are difficulties in obtaining a registration certificate for a medical device.

"Information technologies in medicine give an opportunity for a personalized approach to the treatment of the patient and allow the involvement of various medical specialists to solve the problem of a single patient," said the director general of the FGBIU named after. V.A. Almazova Evgeny Vladimirovich Shlyakhto. The main task of digital medicine is to ensure the availability of high technologies at low costs.

The Ministry of Health of Russia sets the task of organizing telemedicine consultations to be carried out throughout Russia by 2019. First deputy head of the department Igor Kagramanyan explained that the network will be linked to all regional institutions with federal ones.

In April 2018, the government approved rules for interaction between private and public information systems [reference to Decree No. 447 of 12 April 2018]. The document for the first time describes in detail the possibility of private telemedicine services and platforms involved in the storage of medical records, connect to the Unified Health Information System (EGIS) and work with state hospitals. In order to fully operate in the telemedicine services market, the services need to be integrated with the Unified State Health Information System (EGIS) and identify patients through the ESIA [15].

\subsection{Improvement of the business process "Processing of information received by the Federal Telemedicine Center (FTMC)"}

For the coordination and development of telemedicine technologies, in many federal medical centers separate structural divisions - telemedicine centers - have been established. The centers are equipped with the necessary equipment for organizing telemedicine consultations in real time, as well as holding deferred consultations on documents, and selection for treatment.

The Federal Telemedicine Center is a structural subdivision of the federal medical center and interacts with the structural subdivisions of the Unified Telemedicine System of the Ministry of Health of Russia, the upper level of which is the Federal Telemedicine Information System. Consider a generalized model of interaction between the Federal Telemedicine Information System and the FTMC.

The Federal Telemedicine Information System of the Ministry of Health of the Russian Federation includes the following units as functional components: 
- Federal telemedicine advisory centers (FTAC), functioning as part of medical organizations at the federal level, activities in the FTAC are carried out by medical consultants;

- The Federal Coordination and Technical Center (FCTC), functioning on the basis of FGBU VCMC "Protection". FCTC solves the tasks of management, organizational and methodological and technical support of the telemedicine system of the Ministry of Health of Russia;

- The Federal Data Processing Center (FDC) of the Unified State Information System of the Ministry of Health of the Russian Federation (USIS), whose main task is to locate and operate a telemedicine electronic registry and a central archive of medical images.

Information flows are broadcast between the Federal Telemedicine System of the Ministry of Health and regional telemedicine information systems of the subjects of the Russian Federation. To manage information flows (telemedicine requests and conclusions of medical consultants), the FTAC uses automated workstations (AWPs) of dispatchers and telemedicine center operators. Data from the regional telemedicine system (TMS) is received by the Federal Data Processing Center. In parallel, the request for the provision of medical assistance is received by the FTAC. The operator of the FTAC makes a request for the provision of the required information to the Federal Processing Center. If the required data are available, they are provided to the FTAC with the appropriate technical and methodological support of the FCTC. If there is no necessary information in the Federal Data Processing Center, a request is made to the regional TAS. A generalized model of information exchange between the components of the Unified Telemedicine System of the Russian Ministry of Health is presented in Fig. 3.

Consider the existing business process for the formation of a request from a regional health facility in the FTMC. There are the following channels for information entry into the FTMC:

- Federal telemedicine information system of the Ministry of Health of Russia;

- the documents must be submitted in accordance with the order of the Ministry of Health of the Russian Federation of December 29, 2014 N 930n "On Approving the Procedure for the Organization of Providing High-Tech Medical Care Using a Specialized Information System" [16, 17].

An employee of the FTMC checks the package of documents received by the medical center for the completeness of the information provided. If the data entered into the FTMC meets the requirements for the completeness and correctness of the presentation format, the employee of the FTMC will enter the data into MS Excel. The employee in charge of storing the received data analyzes the data and transfers it to the network folder for the doctor in accordance with the disease code. From the folder, the data is reviewed and analyzed by the doctor for a more accurate diagnosis and clarification of the possibility of appointing the date of hospitalization or another treatment option. If the data do not meet the requirements regarding the lack of completeness of the information provided, the employee of the FTMC sends a request to the regional health facility to provide the missing information. The upper level of the business process is shown in Fig. 4 [18]. 


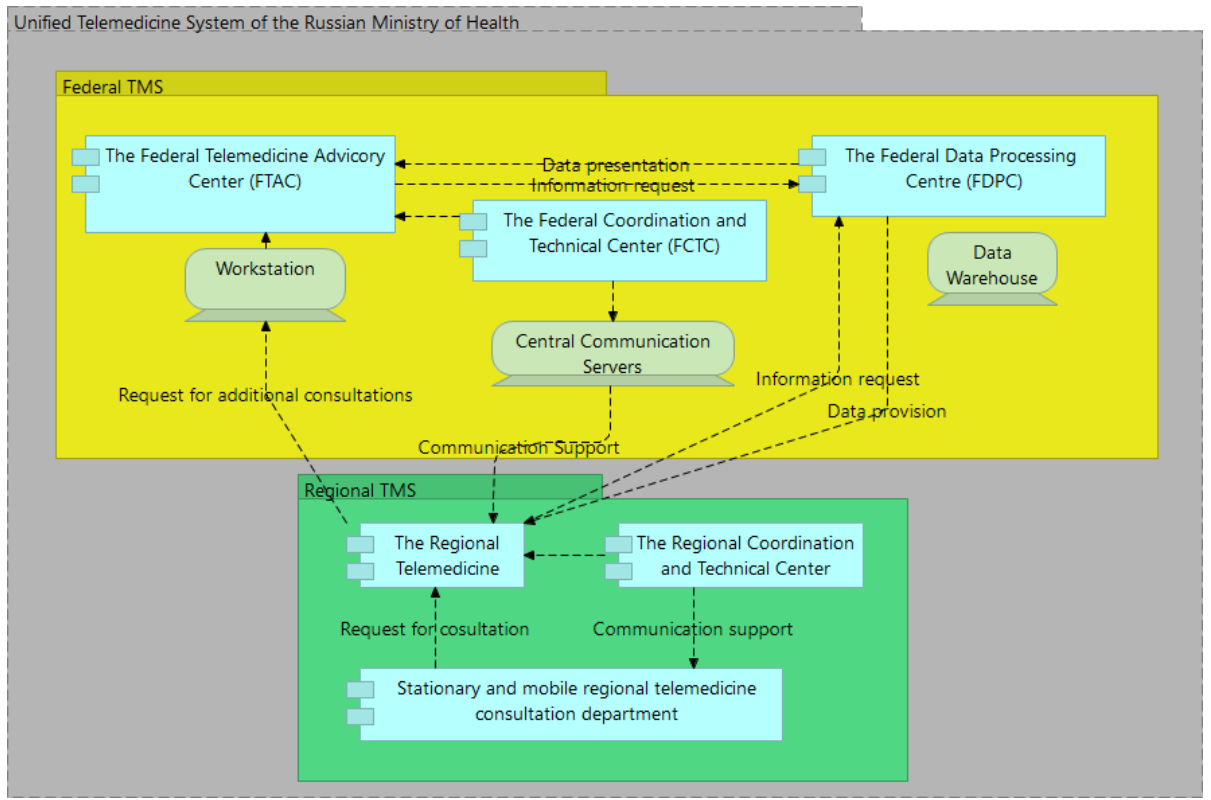

Fig. 3. A generalized information exchange model between the components of the Unified Telemedicine System of the Russian Ministry of Health.

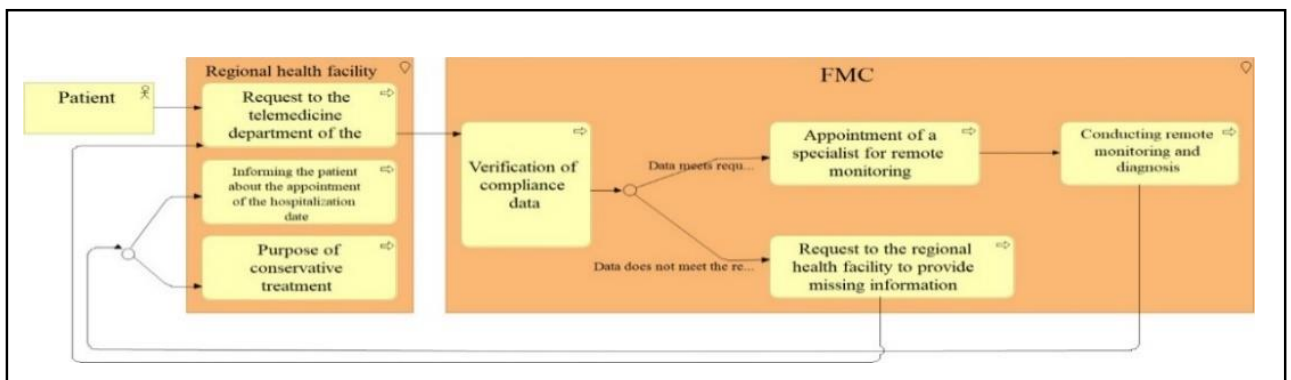

Fig. 4. The upper level of the business process.

The detailed decomposition of the top-level process is done in UML notation (see Fig. 5). 


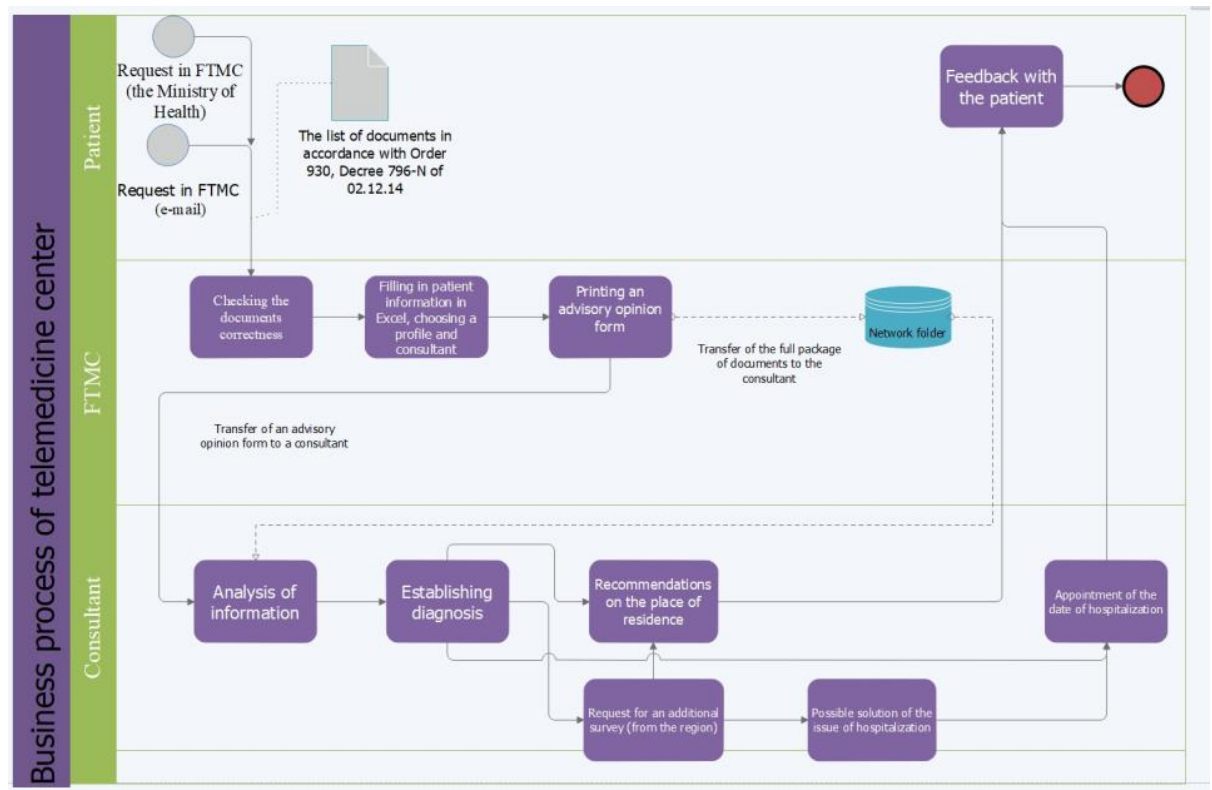

Fig. 5. Business process "Processing of information received in the FTMC" "as is".

As a result of the analysis of the FTMC activities, namely, the business process "Processing of information received by the FTMC", the following problems were identified:

- patient data entry from the region is carried out manually by an employee of the FTMC into the MS Excel database, the patient data is not automatically transferred to the MIS of the FMC when the possibility of treating the patient in the FTMC;

- data on the patient, including the results of clinical diagnostic (CD) studies from theregion, are not stored in the accounting system. The information is stored locally in the network folder. The patient information recorded in the Excel database is not associated with the information located in the network folder. Thus, the basic principle of the accounting system is not realized - data integrity;

- there is no integration of various components of the federal telemedicine system of the Ministry of Health of Russia in terms of data exchange between the Federal Portal of the Ministry of Health of the Russian Federation and the FTMC.

These problems reduce the effectiveness of the using telemedicine technologies in the medical care provision. Solving these problems in part or in full will improve the quality of medical care based on telemedicine technologies [19].

The existing business process requires optimization in terms of information data exchange. Employees enter the primary information first into the MS Excel file, then the data is reanalyzed and transferred to the network folder for the consultant, who in turn decides on the possibility of hospitalization. At the same time, information exchange is carried out manually, there is no information integrity regarding the storage and processing of data coming from the regional health facility. In addition, there is a question of integrating the data coming through the portal of the Ministry of Health of the Russian Federation and transmitting data about patients who are being assigned the date of hospitalization to the medical information system (MIS) of the FMC. 


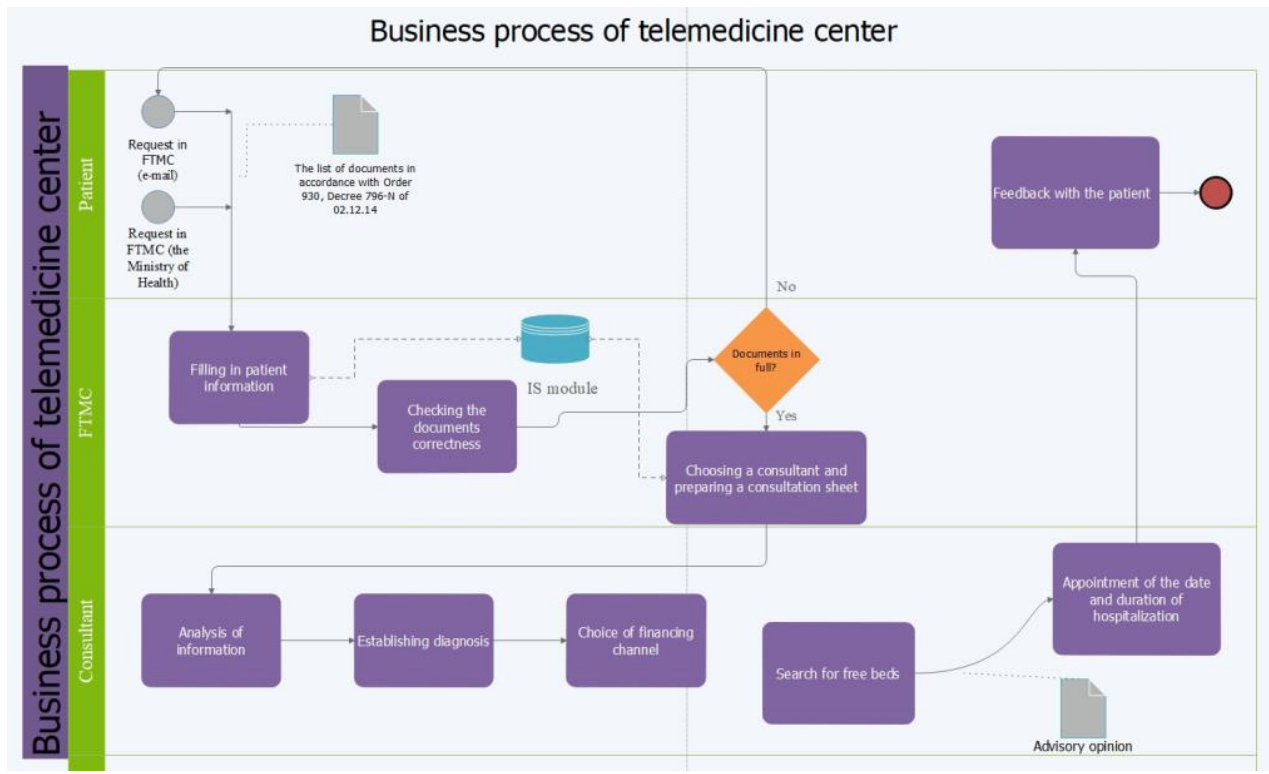

Fig. 6. Business process "Processing of information received in the FTMC" "to be".

To solve the problem of improving the model of information data exchange, it is proposed to change the business process and implement appropriate IT support. The business process "to be" is presented as a UML diagram in Fig. 6. The data from the federal telemedicine information system of the Ministry of Health of Russia enter the module of the information system by entering information by an employee of the telemedicine center. In the absence of a full package of documents, the employee sends a request to the regional health facility. The absence of any document, which is mandatory, does not allow the employee to send the received documents for processing. If a full package of documents is provided, the choice of a consulting doctor takes place and a consultation sheet for the patient is prepared. Further, the consultant analyzes information about the patient, performs the diagnosis and establishes a financing channel. The list of the advisory opinion is formed to determine the date of hospitalization of the patient.

\subsection{The economic efficiency justification of the suggested business process model}

The main parameters used in the evaluation of the suggested business processes model [20].

- the cost of telemedicine counseling (Table 2) [21];

- processing time of on-line requests;

- the number of the telemedicine center consultations.

Table 2. Comparative analysis of the telemedicine and conventional medical consultations cost in Russia.

\begin{tabular}{|c|c|l|}
\hline City/Region & $\begin{array}{c}\text { Telemedicine } \\
\text { consultation's, cost, rub. }\end{array}$ & $\begin{array}{l}\text { Ordinary consultation's } \\
\text { cost, rub. }\end{array}$ \\
\hline Moscow & $450-1000$ rub. & $800-1700$ rub. \\
\hline Saint-Petersburg & $450-800$ rub. & $800-1500$ rub. \\
\hline $\begin{array}{c}\text { Privolzhsky Federal } \\
\text { District }\end{array}$ & $250-550$ rub. & $400-800$ rub. \\
\hline Siberia and the Far East & $200-550$ rub. & $300-700$ rub. \\
\hline
\end{tabular}


As a result of the business processes reengineering of the telemedicine center, the telemedicine consultation's cost is lower in comparison with the traditional consultation, provided that we take into account the costs of transporting the patient, the IT support for the process, etc.

As result we can see significant influence of business processes reengineering of the telemedicine center on the medical organization's activity. From the point of view of the costs formation for the telemedicine services development, the proposed business process reengineering in term the remote patient consultation and monitoring system implementation, remote telemetry, tele-education will improve the data accuracy that the accounting system operates. Since the planning of the patient's treatment course is based on the data analysis obtained for the previous periods, the recorded actual data quality will also improve the quality of the forecasts made on their basis.

The doctor weekly reviews the data in the patient's diary, and in case of serious parameters deviations receives a notice about the need to immediately look into the patient record. A specialist can send a patient a variety of questionnaires to objectify the current state of the observed, and he, in turn, ask questions, ask for comment on the results of the latest tests and receive an answer within 12 hours. As a result, the treatment course is adjusted, additional examinations are made, and if necessary, the patient is invited to a full-time consultation.

Telemedicine reduces the number of time-consuming face-to-face visits, moving counseling "home." Relatively speaking, if the patient needs to visit the doctor 4-5 times a year, he usually comes only twice, the rest of the consultation can be received remotely. This will increase the amount of assistance provided to patients without reducing its quality.

The proposed business processes reengineering and the corresponding information exchange model was proposed and tested in one of the Russian Federal Medical Centers. The processing time of on-line requests has been reduced from 20 minutes per request to 15 minutes on average. This is about $15 \%$ of the time savings. For a year and a half (2016-2017 years), the number of consultations conducted by the telemedicine center increased from 1.5 to 5.5 thousand. The number of consultations in the center has increased more than 3 -fold [22].

\section{Conclusion}

The development of telemedicine technologies in Russia in the provision of medical care to patients can undoubtedly become a strategic solution for many medical problems in Russia associated with early diagnosis, screening of the population, and rendering assistance to patients in the acute period of the disease.

Already today, working in unified information services, doctors have the opportunity, through on-line consultations in the "doctor-doctor" mode, the prompt processing of images and information, to shorten the time of describing the research and transferring to the clinician a few times.

The development of the legislative framework in the field of telemedicine also stimulates the market for remote monitoring of health indicators. Monitoring the patient's condition with the help of mobile devices is legal and remains one of the most promising areas of business.

The issues of economic and medical effectiveness of the use of telemedicine technologies remain open in many aspects. However, it is obvious this medicine sphere is promising provided that the business processes are restructured, that the information exchange models are developed and that the legislative base is improved. 
The proposed of business processes reengineering and the corresponding information exchange model will improve the medical organization indicators: cost, quality, service, time to process.

\section{Discussion}

However, there are a number of risks in the telemedicine services provision. While the issue with the system of authorization and data encryption has not been resolved. In the unified state health information system (USHIS), the law not allowed to include service providers and private medical institutions.

Without authorization or without an electronic signature in the "consent to the processing of data" medical services carry out is prohibited.

Russia needs to improve the regulatory framework: it is necessary to clarify the standards for the medical care provision. When providing medical services in the "ordinary" (internal) mode, it is not always possible to determine unambiguously whether the methods chosen by the doctor are correct to assist the patient. There is a risk that the margin of safety and adequacy of treatment will be even more difficult to establish for telemedicine services. In this regard, it is necessary to determine the criteria by which both the medical specialists and patients will understood the advisability and specific assistance.

The reported study was funded by RFBR according to the research project № 19-010-00579.

\section{References}

1. http://www.avilab.ru/kn-base/60/30157, last accessed 2018/11/20 (Last accessed 24.11.2018)

2. R.L. Bashshur, Telemed. J. 1(1), 34-38 (1995)

3. M.A. Goldberg, Telemed. J. 1(1), 20-25 (1995)

4. D. Kim, J. Cabral, Y. Kim, Networking Requirement and the Role of Multimedia Systems in Telemedicine (Image Computing Systems Laboratory. Univ. of Washington, 1995)

5. R.M. Yusupova, R.I. Polonnikov, Telemedicine. New information technologies on the XXI century threshold (Anatolia, St. Petersburg, 1998)

6. https://www.thelancet.com/journals/lancet/article/PIIS0140-6736(95)90054-3/abstract

7. https://uk.sagepub.com/en-gb/eur/journal-of-telemedicine-and-telecare/journal202189

8. I.A. Koshelev, Medical almanac 1, 13-17 (2010)

9. V. Duke, V. Emmanuel, Information technologies in biomedical research (Peter, St. Petersburg, 2003)

10. https://www.zelis.com/resource/the-economics-of-telemedicine (Last accessed 12.11.2018)

11. http://spb.rbcplus.ru/news/58167f3f7a8aa940304bdb4b (Last accessed 14.11.2018)

12. https://finance.rambler.ru/economics/37365451-teleuskorenie (Last accessed 25.11.2018)

13. https://www.ey.com/Publication/vwLUAssets/ey-health-care-report-2017rus/\$FILE/ey- health-care-report-2017-rus.pdf (Last accessed 22.11.2018)

14. http://tele.med.ru/stat_pub.htm (Last accessed 13.11.2018)

15. https://vademec.ru/news/2018/04/19/pravitelstvo-predlozhilo-chastnym-operatorampodklyuchitsya-k-egisz (Last accessed 17.11.2018) 
16. The Federal Law of Russian Federation of 29 July 2017 № 242-FZ

17. Order of the Ministry of Health of the Russian Federation of November 30, 2017 № 965n

18. A.A. Lepekhin, V.M. Iliashenko, Week of Science of SPbPU materials of a scientific conference with international participation, 286-288 (2017)

19. I.V. Ilin, A.I. Levina, O.Yu. Iliashenko, 29th International Business Information Management Association Conference - Education Excellence and Innovation Management through Vision 2020: From Regional Development Sustainability to Global Economic Growth 2017, 1822-1831 (2017)

20. O.V. Rostova, I.V. Ilin, Science and business: ways of development 2(68), 30-35 (2017)

21. https://mhealthrussian.wordpress.com/ 2018/04/17 (Last accessed 28.11.2018)

22. http://www.almazovcentre.ru/wp-content/uploads/GA_9_2017_13_10_pravka_7.pdf (Last accessed 30.11.2018) 